\title{
Minireviews
}

\section{Contrast Induced Acute Kidney Injury and Direct Cytotoxicity of lodinated Radiocontrast Media on Renal Proximal Tubule Cells}

\author{
Dakota B. Ward and Monica A. Valentovic \\ Department of Biomedical Sciences, Toxicology Research Cluster, Joan C. Edwards School of Medicine, Marshall University, \\ Huntington, West Virginia
}

Received February 11, 2019; accepted May 16, 2019

\begin{abstract}
The administration of intravenous iodinated radiocontrast media $(\mathrm{RCM})$ to visualize internal structures during diagnostic procedures has increased exponentially since their first use in 1928. A serious side effect of RCM exposure is contrast-induced acute kidney injury (Cl-AKI), which is defined as an abrupt and prolonged decline in renal function occurring 48-72 hours after injection. Multiple attempts have been made to decrease the toxicity of RCM by altering ionic strength and osmolarity, yet there is little evidence to substantiate that a specific RCM is superior in avoiding $\mathrm{Cl}-\mathrm{AKI}$. RCM-associated kidney dysfunction is largely attributed to alterations in renal hemodynamics, specifically renal vasoconstriction; however, numerous studies indicate direct cytotoxicity as a source of epithelial damage.
\end{abstract}

Exposure of in vitro renal proximal tubule cells to RCM has been shown to affect proximal tubule epithelium in the following manner: 1) changes to cellular morphology in the form of vacuolization; 2) increased production of reactive oxygen species, resulting in oxidative stress; 3) mitochondrial dysfunction, resulting in decreased efficiency of the electron transport chain and ATP production; 4) perturbation of the protein folding capacity of the endoplasmic reticulum (ER) (activating the unfolded protein response and inducing ER stress); and 5) decreased activity of cell survival kinases. The present review focuses on the direct cytotoxicity of RCM on proximal tubule cells in the absence of in vivo complications, such as alterations in renal hemodynamics or cytokine influence.

\section{Introduction}

Intravenous radiocontrast media ( $\mathrm{RCM})$ administration during procedures such as percutaneous coronary intervention and cardiac angiography is associated with contrast-induced acute kidney injury (CI-AKI). CI-AKI dysfunction ranges from asymptomatic increases in serum creatinine $(\mathrm{SCr})$ to permanent renal damage requiring dialysis (Brown et al., 2016). CI-AKI is defined as a $0.5 \mathrm{mg} / \mathrm{dl}$ increase in $\mathrm{SCr}$ or a greater than $25 \%$ increase of baseline SCr peaking 3-5 days after administration and returning to baseline within 10-14 days in the absence of other contributing factors (Thomsen and Morcos, 2003; Mehran and Nikolsky, 2006). Although the exact mechanisms of RCM nephrotoxicity remain to be elucidated, potential mechanisms include altered renal hemodynamics and direct cytotoxicity to

D.B.W. was partially supported by a West Virginia National Aeronautics and Space Administration Space Consortium Graduate Fellowship.

https://doi.org/10.1124/jpet.119.257337. renal epithelium resulting in increased reactive oxygen species (ROS) and oxidative damage. Renal ischemia is a complex result of severe renal vasoconstriction, decreased oxygen supply, and increased oxygen demand within the renal outer medulla (Yang et al., 2018a). Although a vast number of clinical reports and observational studies have explored the incidence of CI-AKI following administration of RCM, most finding significant risk, little is known about the direct cellular toxicity induced by RCM. To determine the source of RCMinduced cytotoxicity, in vitro models must be implemented to eliminate renal hemodynamic and inflammatory responses to RCM administration. This minireview briefly discusses the characterization of RCM, renal pathogenesis, and risk factors involved in CI-AKI; the direct toxic effects of RCM on cellular antioxidant systems, mitochondria, endoplasmic reticulum (ER), and unfolded protein response (UPR); and the activity of stress kinases in in vitro systems; and addresses current and experimental preventative measures for CI-AKI.

ABBREVIATIONS: ACEI, angiotensin-converting enzyme inhibitor; ARB, angiotensin-II receptor blocker; CHF, congestive heart failure; Cl-AKI, contrast-induced acute kidney injury; eGFR, estimated glomerular filtration rate; ER, endoplasmic reticulum; GFR, glomerular filtration rate; HK-2, human kidney proximal tubule epithelial cell; HOCM, high-osmolar contrast media; IOCM, iso-osmolar contrast media; JAK, Janus kinase; JNK, cJun N-terminal kinase; LOCM, low-osmolar contrast media; MAPK, mitogen-activated protein kinase; MDCK, Madin-Darby Canine Kidney; MnSOD, manganese superoxide dismutase; NAC, $N$-acetylcysteine; NO, nitric oxide; NSAID, nonsteroidal anti-inflammatory drug; PT, proximal tubule; RCM, radiocontrast media; ROCK, Rho-associated protein kinase; ROS, reactive oxygen species; SCr, serum creatinine; STAT, signal transducer and activator of transcription; TAL, thick ascending limb; UPR, unfolded protein response. 


\section{Radiocontrast Media}

The first RCM developed for intravenous administration (uroselectan, diodrast, and hippuran) were synthesized in the late 1920s for use in urography procedures (Swick, 1930). Further advances exploring the relationships between chemical structure, toxicity, and pharmacokinetics resulted in the discovery of acetrizoic acid, the parent compound to all modern RCM agents (Wallingford, 1953). Continuation of these developments led to the detection of RCM that are much more tolerable and increasingly radiopaque compared with early radiopaque compounds.

The first generation of modern RCM was ionic monomer derivatives of acetrizoic acid with osmolalities 5- to 8-fold greater than plasma; these RCM agents were denoted highosmolar contrast media (HOCM). The ionization of early RCM has been associated with many toxic reactions including severe nephrotoxicity (Stokes and Bernard, 1961; Schreiner, 1966), induction of convulsions and seizures (Melartin et al., 1970), pancreatitis in patients undergoing endoscopic retrograde cholangio-pancreatography (Banerjee et al., 1990), severe and potentially fatal thrombi in patients with sickle-cell anemia (McNair, 1972), inhibition of platelet aggregation in vivo and in vitro (Gafter et al., 1979), and blood volume expansion leading to right heart volume overload in patients with poor cardiac function (Widmark, 2007). The theory that first generation RCM ionicity and osmolality were critical contributors to toxicity led to the dimerization or replacement of carboxyl groups with nondissociating hydrophilic groups (Stratta et al., 2012). The resulting generation of RCM consisted of ionic dimers and nonionic monomers that had osmolalities 2- to 3-fold greater than plasma and were labeled low-osmolar contrast media (LOCM). The practice of decreasing RCM osmolality continued, resulting in the third generation of RCM agents of nonionic dimers that exhibit osmolality equivalent to plasma and are designated iso-osmolar contrast media (IOCM).

Following intravenous administration, RCM agents are rapidly diluted and distributed by circulating plasma, reaching concentrations adequate for visualization in approximately 5-10 minutes. First generation RCM agents have low serum-albumin binding of $0 \%-10 \%$, while second and third generation RCM agents show no notable serum-protein binding. RCM agents of all generations show no significant metabolism and are excreted unchanged predominately through the kidneys by glomerular filtration with only $2 \%$ recovered in the feces [Visipaque (iodixanol), 2006; Hypaque (diatrizoate meglumine), 2007]. The pharmacokinetics of RCM can be described by a two-compartment model consisting of a rapid distribution $(\alpha)$ phase and a slow elimination $(\beta)$ phase. For example, in patients with normal kidney function, the $\alpha$ - and $\beta$-phase half-lives for diatrizoic acid are 30 and 120 minutes, respectively; however, in patients with significant renal impairment the $\beta$-phase half-life can be prolonged for several days [Hypaque (diatrizoate meglumine), 2007].

The indications for RCM change in accordance with procedure and risk of the patient involved. All generations of RCM agents are used for angiocardiography, although the use of HOCM is not recommended in patients with renal or cardiac insufficiencies. HOCM agents are used specifically for nonvascular procedures such as pyelography, cystography, and routine computed tomography procedures. LOCM and IOCM agents are used for vascular procedures and multidetector computed tomography (American College of Radiology Committee on Drugs and Contrast Media, 2017). It is perceived that a major portion of the toxicity of RCM is due to elevated osmolalities; however, reducing the osmolality of RCM results in a substantial increase in RCM viscosity (Fig. 1). High injection rates of RCM with higher viscosities could be a contributing factor in stasis of renal tubular function (Ueda et al., 1993). Although there is considerable dissension as to which generation of RCM is the safest, IOCM agents are thought to be optimal since they deliver the most iodine per molecule with the least impact on osmolality. Figure 2 describes the physical structures of various RCM. Table 1 summarizes several parameters of the various generations of RCM.

\section{Renal Pathogenesis}

The administration of intravenous iodinated RCM for diagnostic procedures and medical interventions has increased exponentially since their introduction in the late 1920s. Unfortunately, CI-AKI is the third most common cause of hospital-acquired kidney damage, accounting for $12 \%$ of cases (Nash et al., 2002; Gleeson and Bulugahapitiya, 2004). The level of this dysfunction can vary from a mild increase in SCr to permanent renal failure resulting in dialysis (Brown et al., 2016). Although the definition of CI-AKI varies in the literature, it is generally defined as an absolute increase in $\mathrm{SCr}$ greater than $0.5 \mathrm{mg} / \mathrm{dl}$ or a relative increase of greater than $25 \%$ of baseline $\mathrm{SCr}$ peaking 3-5 days after administration and returning to baseline within 10-14 days (Thomsen and Morcos, 2003; Mehran and Nikolsky, 2006). The incidence of CI-AKI is low (less than $2 \%$ ) in patients with normal to slightly diminished renal function [glomerular filtration rate (GFR) $>60 \mathrm{ml} / \mathrm{min}$ per $1.73 \mathrm{~m}^{2}$ ] (Berns, 1989; Weisbord and Palevsky, 2008); however, in high-risk patients with moderate to severe renal impairment the incidence is as high as 55\% (Mehran and Nikolsky, 2006).

Although the exact mechanisms of toxicity of RCM have not been fully elucidated, it is probable that the acute deterioration of kidney function is caused by a combination of renal medullary hypoxia and direct toxicity to renal epithelial cells. Intravenous administration of RCM induces transient vasodilation of renal vasculature followed by severe, sustained vasoconstriction, specifically of the afferent arterioles, resulting in decreased oxygen supply and oxidative damage to the outer medulla (Persson et al., 2005; Liu et al., 2012). This response is likely due to modifications of endogenous renal vasomodulators, specifically nitric oxide (NO), endothelin, and adenosine (Hall et al., 1992). The production of the vasodilator NO decreases in response to RCM, resulting in exacerbation of renal vasoconstriction (Touati et al., 1993), and the levels of endothelin, a vasoconstrictive peptide released by endothelial cells to maintain blood pressure, have been shown to increase after RCM exposure (Clark et al., 1997). It is also apparent that adenosine plays a role in inducing CI-AKI. Intrarenally administered adenosine produces biphasic hemodynamic alterations that are similar to those induced by RCM (Arend et al., 1987). 


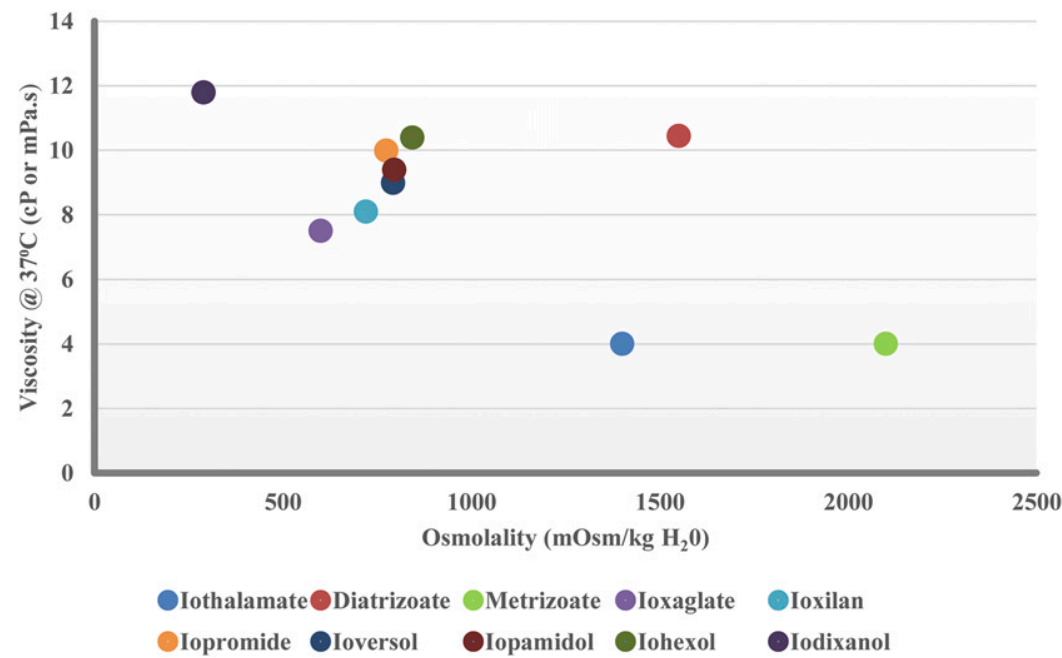

Fig. 1. Relationship between osmolality and viscosity for RCM agents. Maximum concentrations of iodine provided by the manufacturers and corresponding viscosities at $37^{\circ} \mathrm{C}$. Refer to Table 1 for values.

The oxidative damage induced by vasoconstriction is compounded in the relatively hypoxic renal medullae. Under normal physiologic function, the medulla functions at very low $\mathrm{O}_{2}$ tension as the result of limited blood flow and the oxygen shunt caused by the anatomy of the outer medullary vasculature (Heyman et al., 1997; Leong et al., 2007). Along with poor $\mathrm{O}_{2}$ delivery, $\mathrm{O}_{2}$ consumption within the outer medullae is high due to ion reabsorption by the thick ascending limb (TAL) of the nephron (Heyman et al., 1997). The combined effects of low $\mathrm{O}_{2}$ delivery and high $\mathrm{O}_{2}$ consumption render the renal medullae particularly susceptible to hypoxic injury. RCM exposure has been shown to further
A<smiles>CC(=O)Nc1c(I)cc(I)c(C(=O)O)c1I</smiles>

Acetrizoic Acid
B<smiles>CC(=O)Nc1c(I)c(NC(C)=O)c(I)c(C(=O)O)c1I</smiles>

C<smiles>CC(=O)N(CC(O)CO)c1c(I)c(C(=O)NCC(O)CO)c(I)c(C(=O)NCC(O)CO)c1I</smiles>

D<smiles>CNC(=O)c1c(I)c(C(=O)NCC(=O)Nc2c(I)c(C(=O)O)c(I)c(C(=O)NCCO)c2I)c(I)c(N(C)C(C)=O)c1I</smiles>

Iohexol

E<smiles>CC(=O)N(CC(O)CN(C(C)=O)c1c(I)c(C(=O)NCC(O)CO)c(I)c(C(=O)NCC(O)CO)c1I)c1c(I)c(C(=O)NCC(O)CO)c(I)c(C(=O)NCC(O)CO)c1I</smiles>

Fig. 2. Molecular structures of different RCM. Parent compound to modern RCM, acetrizoic acid (A); first generation ionic monomer, diatrizoic acid (B); second generation nonionic monomer, iohexol (C) and ionic dimer, ioxaglate (D); and third generation nonionic dimer, iodixanol (E). 
TABLE 1

Summary of various parameters of RCM

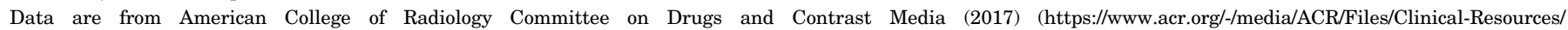
Contrast_Media.pdf).

\begin{tabular}{|c|c|c|c|c|c|c|}
\hline RCM Generation & RCM Name & Osmolality & Iodine Content & Viscosity $25^{\circ} \mathrm{C} / 37^{\circ} \mathrm{C}$ & Ionicity & Iodine-to-Molecule Ratio \\
\hline & & $\mathrm{mOsmol} / \mathrm{kg}$ & $m g \cdot I / m l$ & $c P$ or $m P a \cdot s$ & & \\
\hline \multirow[t]{3}{*}{ First Generation } & Iothalamate & $600-1400$ & $141-282$ & $2.0 / 1.5-6.0 / 4.0$ & Ionic monomer & $1.5: 1$ \\
\hline & Diatrizoate & 1551 & 370 & $16.4 / 10.45$ & Ionic monomer & $1.5: 1$ \\
\hline & Metrizoate & 2100 & 370 & $\mathrm{nr} / 4$ & Ionic monomer & $1.5: 1$ \\
\hline \multirow[t]{6}{*}{ Second Generation } & Ioxaglate & 600 & 320 & $15.7 / 7.5$ & Ionic dimer & $3: 1$ \\
\hline & Ioxilan & 721 & 350 & $16.3 / 8.1$ & Nonionic monomer & $3: 1$ \\
\hline & Iopromide & $328-774$ & $150-370$ & 2.3/1.5-22.0/10.2 & Nonionic monomer & $3: 1$ \\
\hline & Ioversol & $502-792$ & $240-350$ & $4.6 / 3.0-14.3 / 9.0$ & Nonionic monomer & $3: 1$ \\
\hline & Iopamidol & $524-796$ & $250-370$ & $5.1 / 3.0-20.9 / 9.4$ & Nonionic monomer & $3: 1$ \\
\hline & Iohexol & $322-844$ & $140-350$ & 2.3/1.5-20.4/10.4 & Nonionic monomer & $3: 1$ \\
\hline Third Generation & Iodixanol & 290 & $270-320$ & $12.7 / 6.3-26.6 / 11.8$ & Nonionic dimer & $6: 1$ \\
\hline
\end{tabular}

nr, not reported.

decrease $\mathrm{O}_{2}$ tension within the renal medulla and simultaneously induce osmotic diuresis and increase ion transport and $\mathrm{O}_{2}$ consumption at the TAL (Heyman et al., 1991; Cronin, 2010). Additionally, an increase in tubular pressure secondary to RCM-induced diuresis, increased urinary viscosity, and tubular obstruction results in increased oxygen consumption, worsening ischemic damage (Gleeson and Bulugahapitiya, 2004). The combination of alterations in vasomodulators and increased oxidative damage may exert direct tubular and vascular endothelial damage, leading to a vicious cycle of hypoxic damage in the renal parenchyma (Heyman et al., 2010). Although renal papillary necrosis is not a hallmark of CI-AKI, administration of RCM is contraindicated in patients that are undergoing selective or nonselective nonsteroidal anti-inflammatory drug (NSAID) therapy. Concomitant use may aggravate NSAID-induced renal vasoconstriction; therefore, NSAID therapy should be suspended 48 hours prior to RCM administration (Hörl, 2010).

\section{Risk Factors}

Individuals with chronic kidney disease associated with diabetes have the greatest risk for CI-AKI. Other factors that increase the risk for CI-AKI (Table 2) include congestive heart failure (CHF), salt depletion/dehydration, prolonged hypotension, low hematocrit, age $>70$ years, multiple myeloma, sepsis, and concurrent use of certain drugs. Advanced age is an independent predictor of CI-AKI (Gussenhoven et al., 1991). Age-related alterations in renal function including decreases in GFR, tubular secretion, and urine concentrating ability (Sands, 2012; Denic et al., 2016) play a role, as well as the requirement for larger doses of RCM in elderly patients with calcified vasculature (Mehran and Nikolsky, 2006).

Preexisting renal dysfunction is a serious risk factor for CI-AKI development. Due to the inverse relationship between estimated glomerular filtration rate (eGFR) and the risk for CI-AKI, the defined eGFR cutoff point for classifying patients as high risk is $\leq 60 \mathrm{ml} / \mathrm{min}$ per $1.73 \mathrm{~m}^{2}$ (Tsai et al., 2014). The incidence of CI-AKI in patients with underlying chronic renal failure ranges from $14.8 \%$ to $55 \%$, and risk can double in patients with concomitant diabetes mellitus when compared with nondiabetic patients (Mehran and Nikolsky, 2006).
Any extrarenal condition that effectively lowers intravascular volume profoundly increases the risk of CI-AKI. Conditions that reduce effective intravascular volume include $\mathrm{CHF}$, prolonged dehydration, and salt depletion. CHF activates numerous humoral and neurohumoral mechanisms, resulting in sodium and water reabsorption by the kidneys. These mechanisms result in expansion of extracellular fluid by increasing venous capillary pressure, decreasing plasma oncotic pressure, and promoting fluid extravasation and edema formation (Navas and Martinez-Maldonado, 1993). Compromised left ventricle systolic performance, often apparent in CHF patients, has also been linked to increased risk of CI-AKI (MartinParedero et al., 1983; Gruberg et al., 2000). Severe dehydration and salt depletion secondary to abnormal fluid losses associated with insufficient salt intake have been shown to play a role in CI-AKI (Detrenis et al., 2005). Prolonged hypotension as a result of decreased effective intravascular volume or induced by antihypertensive treatment using angiotensin-converting enzyme inhibitors (ACEIs), angiotensin-II receptor blockers (ARBs), or diuretics heighten risk for CI-AKI (Barrett and Parfrey, 1994). Decreased effective intravascular volume contributes to CI-AKI risk by reducing renal perfusion and GFR, resulting in decreased $\mathrm{O}_{2}$ delivery and increased concentration of RCM within the renal tubules and furthering ischemic insult and direct cytotoxicity.

Anemia, or low hematocrit, is an independent risk factor for CI-AKI (Nikolsky et al., 2005; Cho et al., 2010b; Murakami et al., 2013). A study of 510 patients indicated that individuals with lower hematocrit were more likely to develop CI-AKI (Cho et al., 2010b). In an earlier study

TABLE 2

Common predisposing risk factors for CI-AKI

Predisposing Risk Factor

\footnotetext{
Preexisting renal impairment

Diabetes mellitus

Congestive heart failure

Decreased effective intravascular volume

Salt depletion

Dehydration

Prolonged hypotension

Low hematocrit

Age $>70$ years

Muliple myeloma

Sepsis

Concomitant use of various drugs
} 
with patients who displayed both reduced eGFR and hematocrit, rates of CI-AKI were as high as $28.8 \%$, whereas patients with only a diminished eGFR and normal hematocrit had significantly lower rates of CI-AKI (Nikolsky et al., 2005). The mechanism for increased CI-AKI risk in patients with low hematocrit may be partially attributed to diminished oxygen delivery to the kidney, which could increase susceptibility to renal damage. A study of 200 patients revealed less CI-AKI in patients provided oxygen 10 minutes prior to angiography compared with room air (Sekiguchi et al., 2017). These findings suggest sufficient oxygenation may be beneficial to reduce renal damage by RCM, but further studies are warranted to explore the beneficial effect of oxygen.

Many radiologists and physicians consider RCM use a contraindication in patients with multiple myeloma (Bartels et al., 1954; Killmann et al., 1957; Scheitlin et al., 1960). CI-AKI in myeloma patients has been attributed to precipitation of RCM with Tamm-Horsfall glycoprotein, resulting in increased ischemic injury and desquamation of renal proximal tubule (PT) cells (Dawnay et al., 1985). A more recent retrospective study reviewed 46 patients with myeloma who underwent RCM-enhanced computed tomography scans of the chest, abdomen, and pelvis (Pahade et al., 2011). Of the 46 patients, $12(26.1 \%)$ developed CI-AKI; however, there was no significant difference in peak $\mathrm{SCr}$ levels in patients that obtained CI-AKI when compared with the patients that did not. Of the parameters obtained, only the serum levels of $\beta 2$-microglobulin increase in both patients with high tumor burden and decreased renal function, indicating a statistically significant correlation with the development of CI-AKI. According to Pahade and associate a threshold value of $<2.8 \mathrm{mg} / \mathrm{l}$ of $\beta 2$-microglobulin could essentially eliminate the risk of CI-AKI in patients with multiple myeloma. The European Society of Urogenital Radiology concluded multiple myeloma was not a risk factor following evaluation of a retrospective study of 13 studies (Stacul et al., 2018). However, the European Society of Urogenital Radiology concluded that myeloma patients with diminished renal function, dehydration, or hypercalcemia were at a much higher risk for CI-AKI (Stacul et al., 2018).

Sepsis is a life-threatening medical condition most often caused by an overwhelming immune response to a body-wide bacterial infection. Sepsis affects both adult and pediatric patients and is associated with numerous changes to renal function that may be mediated by release of these inflammatory agents as well as direct tubular insult (Alobaidi et al., 2015). Proinflammatory cytokines are released into the bloodstream to combat the infection, triggering widespread inflammation, thrombus formation, and endothelial damage (Cavaillon et al., 2003). In cases of septic shock, side effects include reduced blood pressure, abnormalities in microcirculatory blood flow, coagulopathy, and endothelial dysfunction, resulting in severely reduced oxygen delivery and organ dysfunction or failure (Angus and van der Poll, 2013). However, further studies are needed to evaluate the contribution of renal perfusion since animal and human studies have reported both increased and decreased renal blood flow (Langenberg et al., 2005, 2006). Autopsy series fail to detect extensive cellular necrosis in victims of septic shock (Takasu et al., 2013); this may be due to sepsis promoting mitochondrial damage in renal tubular epithelial cells, resulting in decreased oxygen consumption (Tran et al., 2011). In addition to decreased oxygenation, renal epithelium experience activation of an innate immune response, giving rise to pathogenic oxidative stress and further tissue injury (Wiersinga et al., 2014). The use of nephrotoxic antibiotics to combat the infection can complicate the diagnosis and treatment of sepsis-associated acute kidney injury. Perhaps one (or all) of these factors plays a role in why patients undergoing radiopaque imaging procedures are at increased risk of sepsis (Matejovic et al., 2011). Due to the bidirectional nature of sepsis, additional studies are needed to evaluate the connections between CI-AKI and sepsis.

Concomitant use of nephrotoxic drugs increases the risk of CI-AKI. Aminoglycosides, cyclosporine A, amphotericin B, and cisplatin increase kidney susceptibility to RCM-induced toxicity (Kolonko et al., 1998; Morcos, 1998). Aminoglycosides and amphotericin B exert a direct nephrotoxic effect via disruption of normal phospholipid trafficking and the induction of severe renal vasoconstriction (Swan, 1997; Fanos and Cataldi, 2000). Cyclosporin A impairs lysosomal function and damages both proximal and distal convoluted tubules, resulting in changes to tubulointerstitial transport (Kolonko et al., 1998). Cisplatin and other platinum derivatives impair enzyme function by binding to sulfhydryl groups, resulting in PT cytotoxicity (Hanigan and Devarajan, 2003). Long-term ingestion of high doses of NSAIDs, certain penicillins, and sulfonamides can lead to acute tubulointerstitial nephritis, which increases the risk of CI-AKI (Kolonko et al., 1998; Morcos, 1998). Although the role of ACEIs and ARBs in CI-AKI is controversial, many providers avoid concomitant use (Toprak, 2007). According to the Council on the Kidney in Cardiovascular Disease and the Council for High Blood Pressure Research of the American Heart Association, the use of ACEIs or ARBs in radiopaque imaging procedures depends on multiple factors. ACEIs or ARBs are acceptable and can even improve renal hemodynamics and salt excretion provided that the patient's renal perfusion pressure is adequate and volume depletion is minimal. However, angiotensin II is essential in the autoregulation of GFR and renal perfusion, and the use of these agents in hypovolemic patients can induce a dramatic decrease in GFR and subsequent oliguric or anuric renal failure (Schoolwerth et al., 2001). Conversely, the Kidney Disease Improving Global Outcomes Clinical Practice Guideline for Acute Kidney Injury states that there is not enough evidence to recommend the discontinuation of ACEIs or ARBs prior to RCM administration (Kidney Disease: Improving Global Outcomes Acute Kidney Injury Work Group, 2012). Loop diuretics, specifically furosemide, have been shown to increase the risk of CI-AKI (Majumdar et al., 2009). Other studies have stated that although loop diuretic exposure is associated with acute kidney injury in hospitalized patients, the change in renal function is small and loop diuretic use does not explain the variability in overall renal function (El-Refai et al., 2011).

\section{Cytotoxicity}

The cytotoxic effects of RCM on PT cells have been characterized by vacuoles in the PT cells, increased production 
of ROS and induction of oxidative stress, mitochondrial dysfunction and an ensuing decline in ATP production, activation of UPR and ER stress, and abnormal stress kinase activities (Tervahartiala et al., 1991, 1997; Andersen et al., 1994, 1995). Epithelial PT cell vacuolization is an indicator of drug toxicity and a histopathological feature of CI-AKI. One route in which RCM agents are influxed into PT cells is via pinocytosis. During the process of urine production, RCM is concentrated in the renal tubules. As a result, $\mathrm{PT}$ cells are exposed to increasing concentrations of $\mathrm{RCM}$, inducing a rise in pinocytic vesicles containing RCM, formation of large vacuoles, alterations in renal histology, and epithelial damage (Dickenmann et al., 2008; Andreucci et al., 2014a,b). An early study on vacuolization of PT in response to RCM demonstrated that male Sabra rats experienced vacuolar changes in the early segments of the PT within 120 minutes of administration of $2.9 \mathrm{~g} \cdot \mathrm{I} / \mathrm{kg}$ iothalamate. The changes were described as being similar in nature and closely resembled what has been described in human contrast nephropathy (Heyman et al., 1988). A study performed by Tervahartiala et al. (1991) demonstrated that $3 \mathrm{~g} \cdot \mathrm{I} / \mathrm{kg}$ of diatrizoate or iopromide induced statistically significant PT cell vacuolization within 2 hours of administration in diabetic Wistar rats of both sexes. Iohexol and iotrolan caused longer lasting and more pronounced vacuolization (Tervahartiala et al., 1991). A separate study on male Sprague-Dawley rats showed that a low-level increase in cytoplasmic vacuoles in PT cells occurred in as little as 5 minutes and continued to increase in size and number for 24 hours after single-dose administration of $3 \mathrm{~g} \cdot \mathrm{I} / \mathrm{kg}$ iotrolan (Rees et al., 1997). A more modern study performed on male Wistar rats demonstrated that a concentration as low as $10 \mathrm{ml} / \mathrm{kg}$ of iodixanol can induce vacuolization in PT cells in 24 hours (Nasri et al., 2015). Although RCM agents from each generation induce vacuolization, the lack of in vitro studies makes it impossible to determine if this is a direct toxic side effect of RCM.

CI-AKI is the result of a combination of alterations in renal hemodynamics and toxic renal parenchymal damage. Aside from hypoxia induced by low oxygen supply, it is believed that the latter of the two is due to oxidative stress induced by an increase in ROS. Additionally, exposure to RCM results in diminished availability and activity of cellular antioxidant systems. Under physiologic conditions, the production of ROS within renal parenchyma is connected to tubular transport, specifically in areas of the nephron that have dense mitochondrial populations such as the PT, convoluted tubules, or TAL of the nephron. A major source of production of superoxide anions $\left(\mathrm{O}_{2}^{\circ-}\right)$ and hydroxyl radicals $\left(\mathrm{OH}^{-}\right)$ is found within the mitochondria via NADPH oxidases (Heyman et al., 2010). Additionally, as the consumption of oxygen begins to overwhelm available oxygen during periods of hypoxia, there is an increase in the complete conversion of ATP to hypoxanthine by 5 '-nucleotidase. From this, hypoxanthine is converted to uric acid and hydrogen peroxide $\left(\mathrm{H}_{2} \mathrm{O}_{2}\right)$ via xanthine oxidase. Consequently, $\mathrm{H}_{2} \mathrm{O}_{2}$ and $\mathrm{O}_{2}^{\bullet-}$ can react with $\mathrm{NO}$ to form peroxynitrite, leading to renal vasoconstriction and epithelial damage by decreasing the vasodilatory effects of $\mathrm{NO}$ and interacting with protein and DNA, respectively. Although there is evidence that peroxynitrite can induce a degree of vasodilation initially, long-term exposure to peroxynitrite in an environment

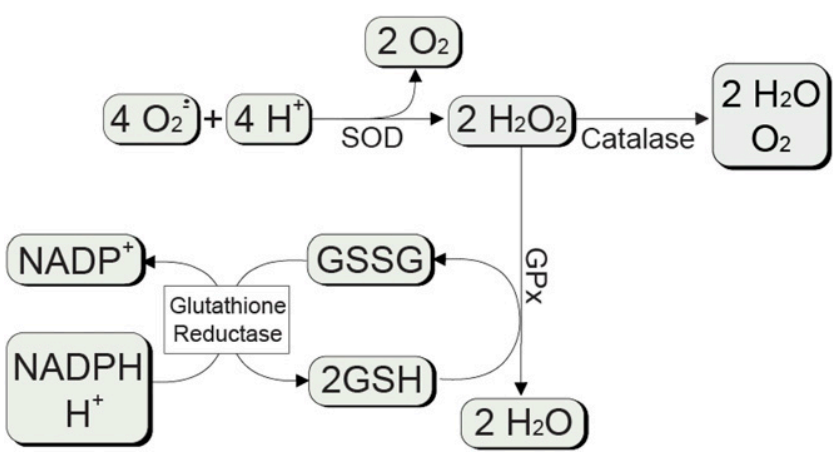

Fig. 3. ROS scavenging pathways in renal epithelial cells.

devoid of NO can lead to irreversible endothelial and epithelial damage (Pacher et al., 2007).

Several experimental studies have shown that RCM agents enhance renal ROS production, resulting in oxidative stress. Huang et al. (2016) noted that exposure of a noncancerous, immortalized human renal proximal tubule epithelial cell line [human kidney 2 (HK-2)] to the HOCM ioxitalamate induced an increase in cytoplasmic ROS production and formation of 8-hydroxy-2' -deoxyguanosine, indicating oxidative damage following 48-hour treatment. A significant increase in cytosolic superoxide formation took place only 2 hours after exposure of HK-2 cells to $150 \mathrm{mg} \cdot \mathrm{I} / \mathrm{ml}$ of the LOCM iohexol (Jeong et al., 2018). A similar study using a canine distal convoluted tubule cell line [Madin-Darby canine kidney (MDCK)] showed that exposure to 50, 100, or $200 \mathrm{mg} \cdot \mathrm{I} / \mathrm{ml}$ of iobitridol, iopamidol, or iodixanol induced a dose-dependent increase in ROS production within 3 hours (Quintavalle et al., 2011). A study performed by Netti et al. (2014) demonstrated that a statistically significant increase in NADPH oxidase-dependent ROS can be seen in HK-2 cells within 30 minutes of exposure to $200 \mathrm{mg} \cdot \mathrm{I} / \mathrm{ml}$ of LOCM iohexol or iopamidol. An increase in intracellular ROS can be seen regardless of generation of RCM.

Although there are several in vitro studies pertaining to the effect of RCM on the production of ROS, very little has been done to examine the source of ROS production. For instance, a rise in ROS concentrations could be, in part, due to a reduction in the efficacy of intracellular antioxidant systems. Figure 3 shows the intracellular antioxidant systems. At the time of this review, a study performed by Jeong et al. (2018) is a lone study examining RCM effects on intracellular antioxidant systems in vitro. The Jeong group determined that HK-2 cells exposed to $150 \mathrm{mg} \cdot \mathrm{I} / \mathrm{ml}$ of iohexol induced a significant decrease in manganese superoxide dismutase (MnSOD) and glutathione peroxidase after 2 hours (Jeong et al., 2018). It is apparent that there is a significant gap in knowledge pertaining to the effects of RCM on antioxidant systems in vitro; however, the effects of RCM on reduced glutathione, glutathione peroxidase, MnSOD, and catalase have been studied extensively in vivo. A study performed by Gong et al. (2016) determined that male Sprague-Dawley rats exposed to $1.5-2 \mathrm{~g} \cdot \mathrm{I} / \mathrm{kg}$ of iohexol resulted in a decrease in MnSOD and glutathione after 24 hours. In a similar study, Tasanarong et al. (2013) showed that exposing male Sprague-Dawley rats to $1.6 \mathrm{~g} \cdot \mathrm{I} / \mathrm{kg}$ of iopromide induced a significant decrease in MnSOD and catalase after 24 hours. Glutathione, glutathione peroxidase, 
MnSOD, and catalase were all significantly reduced in male Sprague-Dawley rats exposed to $3 \mathrm{~g} \cdot \mathrm{I} / \mathrm{kg}$ of iodixanol (Liu et al., 2018). It should be stated that these changes in cellular oxidant defenses may not be a direct result of RCM toxicity and could be induced, in part, by alterations in renal hemodynamics. Taken together, increased ROS production and a decrease in the efficacy of renal antioxidant systems play important roles in CI-AKI; however, the effects of RCM on antioxidant systems in in vitro systems need to be studied more in depth.

Under normal physiologic conditions, the mitochondria are one of the main sources of intracellular ROS and the main organelle target for ROS (Cho et al., 2010a). Previous studies indicate that mitochondrial injury plays an important role in various types of acute kidney injury (Xiao et al., 2014; Tang et al., 2018). Humes et al. (1987) noted that PT segments isolated from New Zealand white rabbits incubated with diatrizaote demonstrated significant reductions in basal and uncoupled respiration and intracellular ATP levels, indicating an interaction between diatrizoate and PT cell mitochondria. A follow-up study using the same model compared the mitochondrial toxicity of diatrizoate and iopamidol (Messana et al., 1988). Messana's group (1988) determined that diatrizoate induced greater reductions in intracellular ATP, basal respiration, and uncoupled respiration when compared with iopamidol, and both RCM agents were toxic when compared with control. Messana et al. (1990) continued their studies of the effects of RCM on isolated proximal tubules by comparing the mitochondrial toxicity of the nonionic monomer iopamidol and ionic dimer ioxaglate, and determined that both RCM agents induced mitochondrial damage but the differences in direct nephrotoxic potential become insignificant when normalized for iodine content. Exposure of a porcine kidney cell line that express characteristics similar to PT cells (LLC-PK1) to ioversol caused depolarization of mitochondrial membranes and stimulated the release of cytochrome $\mathrm{c}$ activating caspase-9 through the action of the adaptor molecule apoptotic protease-activating factor-1 (Itoh et al., 2006). Lei et al. (2018) determined that exposure to iohexol or iodixanol induced a significant increase in mitochondrial ROS and mitochondrial membrane potential in HK-2 cells. An in vivo investigation on the effects of RCM on the electron transport chain determined that exposure of male Wistar albino rats to $1.95 \mathrm{~g} \cdot \mathrm{I} / \mathrm{ml}$ of diatrizaote tended to decrease renal complex I and III activity, although not to a significant degree (Roza et al., 2011). As one would expect, significant mitochondrial dysfunction results in insufficient ATP for a cell to maintain its cellular functions, resulting in activation of the intrinsic apoptotic pathways; however, the source of mitochondrial dysfunction in response to RCM exposure has yet to be identified (Haller and Hizoh, 2004).

The primary role of the ER is the synthesis and folding of secreted, membrane-bound, and some organelle-targeted proteins. The environment within the ER is optimal for protein folding and management, as well as ATP storage and calcium transport (Gaut and Hendershot, 1993). Perturbations of cellular ATP levels, calcium concentration, and/or the redox status within a cell can lead to a decline in the protein folding ability of the ER (Bravo et al., 2013). An accumulation of unfolded or misfolded proteins activates a prosurvival response that is responsible for restoring protein folding function within the ER, which is called the unfolded protein response (Schröder and Kaufman, 2005). Prolonged activation of the UPR will promote a shift from prosurvival to proapoptotic signaling, designated as ER stress (Szegezdi et al., 2006). ER stress can lead to the activation of multiple signaling pathways that induce cellular apoptosis (Fig. 4), and its role in CI-AKI has recently become a topic of interest. An initial study performed by Wu et al. (2010) determined the effects of diatrizoate on rat renal proximal tubule cells (NRK52E). Exposure of NRK52E cells to $40 \mathrm{mg} \cdot \mathrm{I} / \mathrm{ml}$ of diatrizoate induced an increase in multiple ER stress markers including glucose-related peptide-78, protein kinase RNA-like ER kinase, and inositol requiring protein-1 within 24 hours (Wu et al., 2010). An additional study by Wu et al. (2013) on NRK52E cells determined that $40 \mathrm{mg} \cdot \mathrm{I} / \mathrm{ml}$ of diatrizoate induced significant increases in the ER stress markers activating transcription factor 6, C/EBP homologous protein, and the ER stress-dependent caspase, caspase-12, within 24 hours. Peng et al. (2015) showed that HK-2 cells exposed to $40 \mathrm{mg} \cdot \mathrm{I} / \mathrm{ml}$ of diatrizoate induced statistically different increases in glucose-related peptide78 , activating transcription factor 4 , C/EBP homologous protein, and caspase-12 within 4 hours.

Mitogen-activated protein kinases (MAPKs) such as the extracellular signal-regulated kinases 1/2 (or p42/44MAPK), the c-Jun N-terminal kinases (JNKs) 1/2, and p38 MAPK have been shown to be activated in response to ROS (Robinson and Cobb, 1997; Matsuzawa and Ichijo, 2008). The extracellular signal-regulated kinases $1 / 2$ cascade is activated in response to mitogenic and survival stimuli, whereas JNK1/2 and p38 MAPK pathways are stimulated in response to cellular stresses including oxidative agents, hypoxia, UV radiation, and proinflammatory cytokines (Ip and Davis, 1998; Ichijo, 1999). Previous studies have shown that renal epithelial cell exposure to RCM results in activation of the intrinsic apoptotic pathway (Romano et al., 2008). An extensive study performed by Quintavalle et al. (2011) demonstrated the role of stress kinases in the activation of this pathway. MDCK cells were exposed to 50,100 , or $200 \mathrm{mg} \cdot \mathrm{I} / \mathrm{ml}$ iobitridol, iopamidol, or iodixanol for 3 hours to determine the effect of RCM on stress kinases. Each of the tested RCM agents induced a dose-dependent increase in phosphorylated JNK and p38 MAPK within 1 hour, indicating that exposure to RCM does induce activation of the proapoptotic stress kinases. The roles of JNK and p38 MAPK were verified by two methods: pretreating the MDCK cells with the p38 inhibitor 4-[4-(4-fluorophenyl)-2-(4-methylsulfinylphenyl)-1 $H$-imidazol5 -yl]pyridine or transfecting MDCK cells with kinase-dead mutants for p38 or JNK. MDCK cells pretreated with 4-[4-(4fluorophenyl)-2-(4-methylsulfinylphenyl)-1H-imidazol-5yl]pyridine or transfected with kinase-dead mutants were completely protected from the apoptotic effects of all three RCM, verifying the role of stress kinases in CI-AKI (Quintavalle et al., 2011). Another study demonstrated that pretreating HK-2 cells with JNK inhibitor anthra[1,9-cd] pyrazol-6 $(2 H)$-one or p38 inhibitor SB203580 significantly decreased cleaved caspase-3 activation and increased prosurvival protein bcl-2 after exposure to $200 \mathrm{mg} \cdot \mathrm{I} / \mathrm{ml}$ iopamidol (He et al., 2016). A more recent study on LLC-PK1 cells determined that $25 \mathrm{mg} \cdot \mathrm{I} / \mathrm{ml}$ of iodixanol will induce increases in activated p38 MAPK, JNK, and extracellular signalregulated kinase after 24 hours of exposure (Lee et al., 2018). 


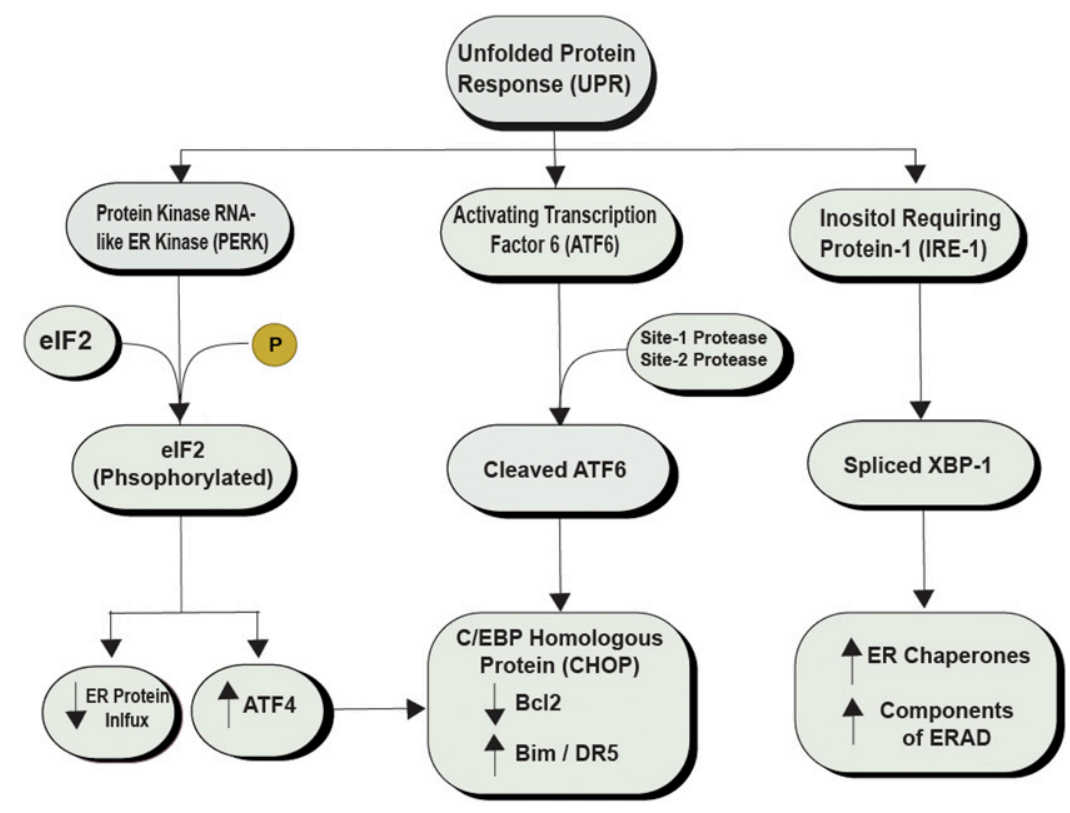

Fig. 4. Pathways involved in the UPR.

Additional kinases important to cellular survival that are affected by RCM exposure include protein kinase B, PTEN-induced putative kinase, Rho-associated protein kinase (ROCK), Janus kinases (JAKs), and signal transducer and activator of transcription (STAT) proteins. A study performed by Xie et al. (2017) on the effects of ioversol on HK-2 cells indicated that 30-minute exposure to $100 \mathrm{mg} / \mathrm{ml}$ of ioversol significantly decreases the presence of phosphorylated protein kinase B while simultaneously inducing caspase-3 cleavage and apoptosis. This discovery demonstrates that the phosphoinositide-3 kinase/protein kinase $B$ pathway may play a role in cellular fate after exposure to RCM. Renal tissues extracted from male Sprague-Dawley rats that were exposed to $12.25 \mathrm{~g} \cdot \mathrm{I} / \mathrm{kg}$ iohexol demonstrated a significant increase in PTENinduced putative kinase (Yang et al., 2018b). Activation of PTEN-induced putative kinase indicates an increase in mitophagy, resulting in decreased ATP production and energy failure. ROCK plays an important role in various cellular processes including cell adhesion, migration, proliferation, cytokine activation, inflammatory cell migration, smooth muscle cell contraction, and cell cycle regulation. Inhibition of Rho-ROCK pathways has been shown to diminish CI-AKI in vivo ( $\mathrm{Su}$ et al., 2014; Wang et al., 2018); however, the relationship between CI-AKI and ROCK has not been explored in vitro. The role of the JAKSTAT pathway was determined in a study performed by Yokomaku et al. (2008). Pretreating male Sprague-Dawley rats or LLC-PK1 cells with asialoerythropoietin or erythropoietin activated JAK2 and STAT5 and attenuated ioversol-induced nephropathy or cellular injury, indicating that the JAK-STAT pathway may play a role in CI-AKI (Yokomaku et al., 2008).

Calcium overload within renal parenchyma is also thought to play a role in CI-AKI via ROS overproduction, p38 MAPK activation, and endothelin activation and release (Humes et al., 1987; Duan et al., 2000; Schick et al., 2002; Yang and Yang, 2013; Jin et al., 2015). However, the initial source of intracellular calcium overload has not been fully elucidated and could result from ER or mitochondrial dysfunction, inhibition of $\mathrm{Na} / \mathrm{K}$-ATPase, or changes in function of the $\mathrm{Na} / \mathrm{Ca}$ exchanger system (Yang and Yang, 2013; Yang et al., 2013; Krebs et al., 2015).

\section{Interventions for Cytotoxicity by Hydration, Drugs, and Natural Products}

Adequate hydration is the gold standard for prevention of CI-AKI. The rationale is that forced or adequate hydration induces an expansion of intravascular volume, suppression of renin-angiotensin cascade, reduction of renal vasoconstriction and hypoperfusion, and increases urine output (Andreucci et al., 2014a,b). Higher urine output is associated with a lower incidence of CI-AKI due to the decreased time of tubular RCM exposure (Solomon and Dauerman, 2010). Unfortunately, high infusion rates can result in a volume overload and initiate pulmonary edema in patients with preexisting cardiac impairment (Chen et al., 2018). Substantial current research has focused on developing a potential nephroprotective agent.

The most explored strategy in the prevention of CI-AKI is the use of antioxidants to decrease contrast-induced oxidative stress. Common antioxidants have been studied including $N$-acetylcysteine (NAC), ascorbic acid, and $\alpha / \gamma$-tocopherol. In vitro studies have provided consistent results for protection by NAC. NAC was protective for IOCM and LOCM cytotoxicity in LLC-PK1, MDCK, and human embryonic kidney 293 cells. At a concentration of $200 \mathrm{mg} \cdot \mathrm{I} / \mathrm{ml}$ of iobitridol and iodixanol and an incubation time of 3 hours, pretreatment with NAC protected the three cell lines from RCM-induced apoptosis (Romano et al., 2008). Yang et al. (2014) demonstrated that NRK-52E cells pretreated with low concentration NAC (10 $\mathrm{mmol} / \mathrm{l})$ before being exposed to 50,100 , and $150 \mathrm{mg} \cdot \mathrm{I} / \mathrm{ml}$ of iopromide for 4 hours significantly decreased early stage apoptosis as seen by annexin $\mathrm{V}$ and propidium iodide staining. The aforementioned Romano et al. (2008) study also examined the 
protective effects of ascorbic acid (vitamin C) in vitro. These authors demonstrated that 2-hour pretreatment with ascorbic acid prevented high concentration IOCM- and LOCMinduced apoptosis in a dose-dependent fashion; however, NAC was more effective than ascorbic acid at preventing RCM-induced cytotoxicity (Romano et al., 2008). Unfortunately, the protective effects of $\alpha / \gamma$-tocopherol on CI-AKI have not been studied in vitro.

Although certain antioxidants have been shown to be protective against CI-AKI in vitro, the results from a clinical standpoint are inconclusive. Numerous clinical studies have shown NAC to be a potentially effective strategy for the prevention of CI-AKI (Tepel et al., 2000; Briguori et al., 2004, 2007); other studies have concluded that NAC alone or in combination with ascorbic acid was not beneficial to patients (Yeganehkhah et al., 2014; Palli et al., 2017). Further studies are needed to evaluate the long-term clinical benefits in patients since a study in over 5000 patients concluded that NAC was not beneficial when evaluating outcomes 90 days after angiography in high renal risk patients (Weisbord et al., 2018). Antioxidant vitamins $\alpha / \gamma$-tocopherol (vitamin E) have also been shown to be useful in the prevention of CI-AKI in a clinical setting (Spargias et al., 2004; Briguori et al., 2007; Tasanarong et al., 2013). A study performed by Kongkham et al. (2013) on male Sprague-Dawley rats demonstrated that pretreatment with 250 or $500 \mathrm{mg}$ vitamin E prior to induction of CI-AKI with $1.6 \mathrm{~g} \cdot \mathrm{I} / \mathrm{kg}$ iopromide significantly decreased tubular necrosis, PT cell congestion, and interstitial edema while simultaneously increasing total antioxidant capacity and MnSOD activity when compared with nonpretreated rats.

3-Hydroxy-3-methyl-glutaryl-coenzyme A reductase inhibitors, or statins, are a class of lipid lowering medications specifically used in the treatment of cardiovascular disease. Statins are thought to protect against RCM cytotoxicity by increasing heme oxygenase-1 production and diminishing the activity of NADPH oxidase, resulting in the reduction of ROS formation and oxidative stress induced by RCM (Grosser et al., 2004; Stoll et al., 2004). Cell culture results have been promising since MDCK and HK-2 cells pretreated with $0.2 \mu \mathrm{M}$ atorvastatin for at least 6 hours had higher cell viability and subsequent decrease in RCM-induced apoptosis after 3-hour exposure to $200 \mathrm{mg} \cdot \mathrm{I} / \mathrm{ml}$ iodixanol (Quintavalle et al., 2012). Initial clinical studies suggest statin pretreatment may reduce CI-AKI, especially in high risk patients (Jo et al., 2008; Toso et al., 2010; Tropeano et al., 2016).

Pharmacologic agents used primarily for the treatment of hypertension such as nebivolol, ACEIs, and ARBs have garnered some interest in the prevention of CI-AKI. Nebivolol is a third generation $\beta_{1}$-receptor antagonist that may protect the kidney via its antioxidant and NO-mediated vasodilating properties (Toprak et al., 2008). Toprak et al. (2008) determined the efficacy of nebivolol in preventing CI-AKI initially in female Wistar albino rats pretreated with $2 \mathrm{mg} / \mathrm{kg}$ of nebivolol once daily for five consecutive days prior to administration of $6 \mathrm{ml} / \mathrm{kg}$ of diatrizoate on the fourth day. Pretreatment with nebivolol resulted in a reduction of tubular necrosis, medullary congestion, and tubular casts, as well as an increase in renal NO levels in rats when compared with rats that did not receive nebivolol (Toprak et al., 2008). A more recent study followed the Toprak et al. (2008) study design and determined that pretreatment with nebivolol prior to administration of RCM significantly reduced advanced oxidation protein products and malondialdehyde in serum and kidney tissue and increased total serum NO concentration (Koc et al., 2011). The role of the renin/angiotensin/aldosterone system and renin/angiotensin/aldosterone system-blocking drugs in CI-AKI is controversial. This is due to experimental data suggesting ACEIs or ARBs protect the kidneys from RCM-induced nephrotoxicity, while other claims indicate that renin/angiotensin/aldosterone system-blocking drugs are nephrotoxic and worsen CI-AKI (Ikeda et al., 2006; Rosenstock et al., 2008; Patel et al., 2011). A large prospective study performed by Hölscher et al. (2008) evaluated CI-AKI predictors and long-term outcomes of high-risk patients. The authors noted that decreased eGFR, the use of ACEIs, and postprocedural hemodialysis were independently associated with increased incidence of CI-AKI (Hölscher et al., 2008). The overall lack of in vitro experimentation pertaining to high blood pressure medications is troubling when compared with the amount of clinical data that has been collected. This is an area where more research is necessary to make an accurate prediction of the possible mechanisms involved.

The administration of naturally derived compounds in the prevention of CI-AKI has shown considerable promise in recent years. In vitro polyphenolic compounds such as resveratrol, salvianolic acid B, and epigallocatechin gallate; flavonoid compounds found in Artemisia argyi; and the xanthone compound $\alpha$-mangostin all have demonstrated protective effects against CI-AKI. Resveratrol, a compound found in grape skins, significantly reduced HK-2 cytotoxicity induced by ioxithalamate after 48-hour exposure (Huang et al., 2016). Salvianolic acid B, derived from the traditional Chinese medicine Danshen, decreased renal epithelial damage in male Sprague-Dawley rats exposed to iohexol (Tongqiang et al., 2016). In a similar fashion to salvianolic acid $\mathrm{B}$, epigallocatechin gallate, the major antioxidant component of green tea, reduced the damage induced by iopromide in male Sprague-Dawley rats (Gao et al., 2016). A study performed by Lee et al. (2018) demonstrated that the flavonoid components of Artemisia argyi, also called mugwort, completely prevented the cytotoxic effects induced by iodixanol on LLC-PK1 cells. A separate study performed by Lee et al. (2016) showed that nontoxic concentrations of $\alpha$-mangostin, found in mangosteen, improved the viability of iodixanol-treated LLC-PK1 cells by $90.42 \%$ against contrast-induced apoptotic damage. It is apparent that the nephroprotective effects of certain naturally derived compounds can prevent contrast-induced cytotoxicity both in vitro and in vivo.

\section{Conclusions}

RCM agents are nonbiologically active compounds necessary for a multitude of diagnostic imaging procedures. Modern RCM agents induce severe and prolonged vasoconstriction within the renal medulla and are directly toxic to the extremely metabolically active renal epithelium such as PT cells and the TAL. Exposure to RCM and the consequential epithelial damage results in an increase in ROS and oxidative stress, vacuolization of tubular cells, damage to the mitochondria in the form of decreased respiration and ATP production, perturbations in the protein folding capacity of the ER (resulting in activation of the UPR and ER stress), and decreased activity of survival kinases and 
activation of proapoptotic stress kinases. The current measures to ensure the prevention of CI-AKI are lacking and considerable research needs to be conducted in in vitro studies to determine the source of direct RCM-induced cytotoxicity.

\section{Acknowledgments}

The authors thank Kathleen C. Brown and Jamie Friedman for suggestions and review of the manuscript.

\section{Authorship Contributions}

Wrote or contributed to the writing of the manuscript: Ward, Valentovic.

\section{References}

Alobaidi R, Basu RK, Goldstein SL, and Bagshaw SM (2015) Sepsis-associated acute kidney injury. Semin Nephrol 35:2-11.

Andersen KJ, Christensen EI, and Vik H (1994) Effects of iodinated x-ray contrast media on renal epithelial cells in culture. Invest Radiol 29:955-962

Andersen KJ, Vik H, Eikesdal HP, and Christensen EI (1995) Effects of contrast media on renal epithelial cells in culture. Acta Radiol Suppl 399:213-218.

Andreucci M, Faga T, Pisani A, Sabbatini M, and Michael A (2014a) Acute kidney injury by radiographic contrast media: pathogenesis and prevention. BioMed Res Int 2014:362725.

Andreucci M, Solomon R, and Tasanarong A (2014b) Side effects of radiographic contrast media: pathogenesis, risk factors, and prevention. BioMed Res Int 2014 741018.

Angus DC and van der Poll T (2013) Severe sepsis and septic shock. N Engl J Med 369:840-851.

Arend LJ, Bakris GL, Burnett JC Jr, Megerian C, and Spielman WS (1987) Role for intrarenal adenosine in the renal hemodynamic response to contrast media. $J$ Lab Clin Med 110:406-411.

Banerjee AK, Grainger SL, and Thompson RP (1990) Trial of low versus high osmolar contrast media in endoscopic retrograde cholangiopancreatography. $\mathrm{Br} \mathrm{J}$ Clin Pract 44:445-447.

Barrett BJ and Parfrey PS (1994) Prevention of nephrotoxicity induced by radiocontrast agents. $N$ Engl J Med 331:1449-1450.

Bartels ED, Brun GC, Gammeltoft A, and Gjørup PA (1954) Acute anuria following intravenous pyelography in a patient with myelomatosis. Acta Med Scand 150: 297-302

Berns AS (1989) Nephrotoxicity of contrast media. Kidney Int 36:730-740.

Bravo R, Parra V, Gatica D, Rodriguez AE, Torrealba N, Paredes F, Wang ZV, Zorzano A, Hill JA, Jaimovich E, et al. (2013) Endoplasmic reticulum and the unfolded protein response: dynamics and metabolic integration. Int Rev Cell Mol Biol 301 215-290

Briguori C, Airoldi F, D’Andrea D, Bonizzoni E, Morici N, Focaccio A, Michev I, Montorfano M, Carlino M, Cosgrave J, et al. (2007) Renal Insufficiency Following Contrast Media Administration Trial (REMEDIAL): a randomized comparison of 3 preventive strategies. Circulation 115:1211-1217.

Briguori C, Colombo A, Violante A, Balestrieri P, Manganelli F, Paolo Elia P, Golia B Lepore S, Riviezzo G, Scarpato P, et al (2004) Standard vs double dose of $\mathrm{N}$-acetylcysteine to prevent contrast agent associated nephrotoxicity. Eur Heart $J$ 25:206-211.

Brown JR, Rezaee ME, Nichols EL, Marshall EJ, Siew ED, and Matheny ME (2016) Incidence and in-hospital mortality of acute kidney injury (AKI) and dialysisrequiring AKI (AKI-D) after cardiac catheterization in the National Inpatient Sample. J Am Heart Assoc 5:e02739.

Cavaillon JM, Adib-Conquy M, Fitting C, Adrie C, and Payen D (2003) Cytokine cascade in sepsis. Scand J Infect Dis 35:535-544.

Chen SQ, Liu Y, Bei WJ, Wang Y, Duan CY, Wu DX, Wang K, Chen PY, Chen JY, Tan N, et al. (2018) Optimal hydration volume among high-risk patients with advanced congestive heart failure undergoing coronary angiography. Oncotarget $\mathbf{9}$ : 23738-23748.

Cho DH, Nakamura T, and Lipton SA (2010a) Mitochondrial dynamics in cell death and neurodegeneration. Cell Mol Life Sci 67:3435-3447.

Cho JY, Jeong MH, Hwan Park S, Kim IS, Park KH, Sim DS, Yoon NS, Yoon HJ, Park HW, Hong YJ, et al. (2010b) Effect of contrast-induced nephropathy on cardiac outcomes after use of nonionic isosmolar contrast media during coronary procedure. J Cardiol 56:300-306.

Clark BA, Kim D, and Epstein FH (1997) Endothelin and atrial natriuretic peptide levels following radiocontrast exposure in humans. Am J Kidney Dis 30:82-86.

Cronin RE (2010) Contrast-induced nephropathy: pathogenesis and prevention. Pediatr Nephrol 25:191-204.

Dawnay AB, Thornley C, Nockler I, Webb JA, and Cattell WR (1985) Tamm-Horsfall glycoprotein excretion and aggregation during intravenous urography. Relevance to acute renal failure. Invest Radiol 20:53-57.

Denic A, Glassock RJ, and Rule AD (2016) Structural and functional changes with the aging kidney. Adv Chronic Kidney Dis 23:19-28.

Detrenis S, Meschi M, Musini S, and Savazzi G (2005) Lights and shadows on the pathogenesis of contrast-induced nephropathy: state of the art. Nephrol Dial Transplant 20:1542-1550.

Dickenmann M, Oettl T, and Mihatsch MJ (2008) Osmotic nephrosis: acute kidney injury with accumulation of proximal tubular lysosomes due to administration of exogenous solutes. Am J Kidney Dis 51:491-503.
Duan SB, Liu FY, Luo JA, Wu HW, Liu RH, Peng YM, and Yang XL (2000) Nephrotoxicity of high- and low-osmolar contrast media. The protective role of amlodipine in a rat model. Acta Radiol 41:503-507.

El-Refai M, Krivospitskaya O, Peterson EL, Wells K, Williams LK, and Lanfear DE (2011) Relationship of loop diuretic dosing and acute changes in renal function during hospitalization for heart failure. J Clin Exp Cardiolog 2:1000164.

Fanos V and Cataldi L (2000) Amphotericin B-induced nephrotoxicity: a review. $J$ Chemother 12:463-470.

Gafter U, Creter D, Zevin D, Catz R, and Djaldetti M (1979) Inhibition of platelet aggregation by contrast media. Radiology 132:341-342.

Gao Z, Han Y, Hu Y, Wu X, Wang Y, Zhang X, Fu J, Zou X, Zhang J, Chen X, et al. (2016) Targeting HO-1 by epigallocatechin-3-gallate reduces contrast-induced renal injury via anti-oxidative stress and anti-inflammation pathways. PLoS One 11: e0149032.

Gaut JR and Hendershot LM (1993) The modification and assembly of proteins in the endoplasmic reticulum. Curr Opin Cell Biol 5:589-595.

Gleeson TG and Bulugahapitiya S (2004) Contrast-induced nephropathy. AJR Am J Roentgenol 183:1673-1689.

Gong X, Duan Y, Zheng J, Wang Y, Wang G, Norgren S, and Hei TK (2016) Nephroprotective Effects of N-Acetylcysteine Amide against Contrast-Induced $\mathrm{Ne}$ phropathy through Upregulating Thioredoxin-1, Inhibiting ASK1/p38MAPK Pathway, and Suppressing Oxidative Stress and Apoptosis in Rats. Oxid Med Cell Longev 2016:8715185.

Grosser N, Erdmann K, Hemmerle A, Berndt G, Hinkelmann U, Smith G, and Schröder H (2004) Rosuvastatin upregulates the antioxidant defense protein heme oxygenase-1. Biochem Biophys Res Commun 325:871-876.

Gruberg L, Pinnow E, Flood R, Bonnet Y, Tebeica M, Waksman R, Satler LF, Pichard $\mathrm{AD}$, Kent KM, Leon MB, et al. (2000) Incidence, management, and outcome of coronary artery perforation during percutaneous coronary intervention. $A m J$ Cardiol 86:680-682.

Gussenhoven MJ, Ravensbergen J, van Bockel JH, Feuth JD, and Aarts JC (1991) Renal dysfunction after angiography; a risk factor analysis in patients with peripheral vascular disease. J Cardiovasc Surg (Torino) 32:81-86.

Hall KA, Wong RW, Hunter GC, Camazine BM, Rappaport WA, Smyth SH, Bull DA, McIntyre KE, Bernhard VM, and Misiorowski RL (1992) Contrast-induced nephrotoxicity: the effects of vasodilator therapy. J Surg Res 53:317-320.

Haller C and Hizoh I (2004) The cytotoxicity of iodinated radiocontrast agents on renal cells in vitro. Invest Radiol 39:149-154.

Hanigan MH and Devarajan P (2003) Cisplatin nephrotoxicity: molecular mechanisms. Cancer Ther 1:47-61.

He X, Li L, Tan H, Chen J, and Zhou Y (2016) Atorvastatin attenuates contrastinduced nephropathy by modulating inflammatory responses through the regulation of JNK/p38/Hsp27 expression. J Pharmacol Sci 131:18-27.

Heyman SN, Brezis M, Epstein FH, Spokes K, Silva P, and Rosen S (1991) Early renal medullary hypoxic injury from radiocontrast and indomethacin. Kidney Int 40:632-642.

Heyman SN, Brezis M, Reubinoff CA, Greenfeld Z, Lechene C, Epstein FH, and Rosen S (1988) Acute renal failure with selective medullary injury in the rat. $J$ Clin Invest 82:401-412.

Heyman SN, Rosen S, and Brezis M (1997) The renal medulla: life at the edge of anoxia. Blood Purif 15:232-242

Heyman SN, Rosen S, Khamaisi M, Idée JM, and Rosenberger C (2010) Reactive oxygen species and the pathogenesis of radiocontrast-induced nephropathy. Invest Radiol 45:188-195.

Hölscher B, Heitmeyer C, Fobker M, Breithardt G, Schaefer RM, and Reinecke H (2008) Predictors for contrast media-induced nephropathy and long-term survival: prospectively assessed data from the randomized controlled Dialysis-VersusDiuresis (DVD) trial. Can J Cardiol 24:845-850.

Hörl WH (2010) Nonsteroidal anti-inflammatory drugs and the kidney. Pharmaceuticals (Basel) 3:2291-2321.

Huang YT, Chen YY, Lai YH, Cheng CC, Lin TC, Su YS, Liu CH, and Lai PC (2016) Resveratrol alleviates the cytotoxicity induced by the radiocontrast agent, ioxitalamate, by reducing the production of reactive oxygen species in HK-2 human renal proximal tubule epithelial cells in vitro. Int J Mol Med 37:83-91.

Humes HD, Hunt DA, and White MD (1987) Direct toxic effect of the radiocontrast agent diatrizoate on renal proximal tubule cells. Am J Physiol 252:F246-F255.

Hypaque (diatrizoate meglumine). (2007) Package insert. Amersham-Health, Princeton, NJ.

Ichijo H (1999) From receptors to stress-activated MAP kinases. Oncogene 18:6087-6093. Ikeda N, Nishimura S, Kyo S, Komiyama N, Matsumoto K, Inoue T, and Suzuki H (2006) Valsartan cardio-renal protection in patients undergoing coronary angiography complicated with chronic renal insufficiency (VAL-CARP) trial: rationale and design. Circ J 70:548-552.

Ip YT and Davis RJ (1998) Signal transduction by the c-Jun N-terminal kinase (JNK) -from inflammation to development. Curr Opin Cell Biol 10:205-219.

Itoh Y, Yano T, Sendo T, Sueyasu M, Hirano K, Kanaide H, and Oishi R (2006) Involvement of de novo ceramide synthesis in radiocontrast-induced renal tubular cell injury. Kidney Int 69:288-297.

Jeong BY, Lee HY, Park CG, Kang J, Yu SL, Choi DR, Han SY, Park MH, Cho S, Lee SY, et al. (2018) Oxidative stress caused by activation of NADPH oxidase 4 promotes contrast-induced acute kidney injury. PLoS One 13:e0191034.

Jin S, Orabi AI, Le T, Javed TA, Sah S, Eisses JF, Bottino R, Molkentin JD, and Husain SZ (2015) Exposure to radiocontrast agents induces pancreatic inflammation by activation of nuclear factor $-\kappa \mathrm{B}$, calcium signaling, and calcineurin. Gastroenterology 149:753-764.e11.

Jo SH, Koo BK, Park JS, Kang HJ, Cho YS, Kim YJ, Youn TJ, Chung WY, Chae IH, Choi DJ, et al. (2008) Prevention of radiocontrast medium-induced nephropathy using short-term high-dose simvastatin in patients with renal insufficiency undergoing coronary angiography (PROMISS) trial-a randomized controlled study. Am Heart J 155:499.e1-499.e8. 
Kidney Disease: Improving Global Outcomes Acute Kidney Injury Work Group (2012) KDIGO clinical practice guideline for acute kidney injury. Kidney Int Suppl 2:1-138.

Killmann SA, Gjorup S, and Thaysen JH (1957) Fatal acute renal failure following intravenous pyelography in a patient with multiple myeloma. Acta Med Scand $\mathbf{1 5 8}$ $43-46$

Koc E, Reis KA, Ebinc FA, Pasaoglu H, Demirtas C, Omeroglu S, Derici UB, Guz G, Erten Y, Bali M, et al. (2011) Protective effect of beta-glucan on contrast inducednephropathy and a comparison of beta-glucan with nebivolol and $N$-acetylcysteine in rats. Clin Exp Nephrol 15:658-665.

Kolonko A, Kokot F, and Wiecek A (1998) Contrast-associated nephropathy-old clinical problem and new therapeutic perspectives. Nephrol Dial Transplant 13: 803-806.

Kongkham S, Sriwong S, and Tasanarong A (2013) Protective effect of alpha tocopherol on contrast-induced nephropathy in rats. Nefrologia 33:116-123.

Krebs J, Agellon LB, and Michalak M (2015) $\mathrm{Ca}^{2+}$ homeostasis and endoplasmic reticulum (ER) stress: an integrated view of calcium signaling. Biochem Biophys Res Commun 460:114-121.

Langenberg C, Bellomo R, May C, Wan L, Egi M, and Morgera S (2005) Renal blood flow in sepsis. Crit Care 9:R363-R374.

Langenberg C, Wan L, Egi M, May CN, and Bellomo R (2006) Renal blood flow in experimental septic acute renal failure. Kidney Int 69:1996-2002.

Lee D, Choi YO, Kim KH, Chin YW, Namgung H, Yamabe N, and Jung K (2016) Protective effect of $\alpha$-mangostin against iodixanol-induced apoptotic damage in LLC-PK1 cells. Bioorg Med Chem Lett 26:3806-3809.

Lee D, Kim CE, Park SY, Kim KO, Hiep NT, Lee D, Jang HJ, Lee JW, and Kang KS (2018) Protective effect of Artemisia argyi and its flavonoid constituents against contrast-induced cytotoxicity by iodixanol in LLC-PK1 cells. Int J Mol Sci 19:1387.

Lei R, Zhao F, Tang CY, Luo M, Yang SK, Cheng W, Li XW, and Duan SB (2018) Mitophagy plays a protective role in iodinated contrast-induced acute renal tubular epithelial cells injury. Cell Physiol Biochem 46:975-985.

Leong CL, Anderson WP, O'Connor PM, and Evans RG (2007) Evidence that renal arterial-venous oxygen shunting contributes to dynamic regulation of renal oxygenation. Am J Physiol Renal Physiol 292:F1726-F1733.

Liu N, Chen J, Gao D, Li W, and Zheng D (2018) Astaxanthin attenuates contrast agent-induced acute kidney injury in vitro and in vivo via the regulation of SIRT1/ FOXO3a expression. Int Urol Nephrol 50:1171-1180.

Liu ZZ, Viegas VU, Perlewitz A, Lai EY, Persson PB, Patzak A, and Sendeski MM (2012) Iodinated contrast media differentially affect afferent and efferent arteriolar tone and reactivity in mice: a possible explanation for reduced glomerular filtration rate. Radiology 265:762-771.

Majumdar SR, Kjellstrand CM, Tymchak WJ, Hervas-Malo M, Taylor DA, and Teo KK (2009) Forced euvolemic diuresis with mannitol and furosemide for prevention of contrast-induced nephropathy in patients with CKD undergoing coronary angiography: a randomized controlled trial. Am J Kidney Dis 54:602-609.

Martin-Paredero V, Dixon SM, Baker JD, Takiff H, Gomes AS, Busuttil RW, and Moore WS (1983) Risk of renal failure after major angiography. Arch Surg 118 $1417-1420$

Matejovic M, Chvojka J, Radej J, Ledvinova L, Karvunidis T, Krouzecky A and Novak I (2011) Sepsis and acute kidney injury are bidirectional. Contrib Nephrol 174:78-88

Matsuzawa A and Ichijo H (2008) Redox control of cell fate by MAP kinase: physiological roles of ASK1-MAP kinase pathway in stress signaling. Biochim Biophys Acta 1780:1325-1336.

McNair JD (1972) Selective coronary angiography. Report of a fatality in a patient with sickle cell hemoglobin. Calif Med 117:71-75.

Mehran R and Nikolsky E (2006) Contrast-induced nephropathy: definition, epidemiology, and patients at risk. Kidney Int Suppl 69 (Suppl 100):S11-S15.

Melartin E, Tuohimaa PJ, and Dabb R (1970) Neurotoxicity of iothalamates and diatrizoates. I. Significance of concentration and cation. Invest Radiol 5:13-21.

Messana JM, Cieslinski DA, and Humes HD (1990) Comparison of toxicity of radiocontrast agents to renal tubule cells in vitro. Ren Fail 12:75-82.

Messana JM, Cieslinski DA, Nguyen VD, and Humes HD (1988) Comparison of the toxicity of the radiocontrast agents, iopamidol and diatrizoate, to rabbit renal proximal tubule cells in vitro. J Pharmacol Exp Ther 244:1139-1144.

Morcos SK (1998) Contrast media-induced nephrotoxicity-questions and answers. Br J Radiol 71:357-365.

Murakami R, Kumita S, Hayashi H, Sugizaki K, Okazaki E, Kiriyama T, Hakozaki K, Tani H, Miki I, and Takeda M (2013) Anemia and the risk of contrast-induced nephropathy in patients with renal insufficiency undergoing contrast-enhanced MDCT. Eur J Radiol 82:e521-e524.

Nash K, Hafeez A, and Hou S (2002) Hospital-acquired renal insufficiency. Am $J$ Kidney Dis 39:930-936.

Nasri H, Hajian S, Ahmadi A, Baradaran A, Kohi G, Nasri P, and Rafieian-Kopaei M (2015) Ameliorative effect of green tea against contrast-induced renal tubular cell injury. Iran J Kidney Dis 9:421-426.

Navas JP and Martinez-Maldonado M (1993) Pathophysiology of edema in congestive heart failure. Heart Dis Stroke 2:325-329.

Netti GS, Prattichizzo C, Montemurno E, Simone S, Cafiero C, Rascio F, Stallone G, Ranieri E, Grandaliano G, and Gesualdo L (2014) Exposure to low- vs iso-osmolar contrast agents reduces NADPH-dependent reactive oxygen species generation in a cellular model of renal injury. Free Radic Biol Med 68:35-42.

Nikolsky E, Mehran R, Lasic Z, Mintz GS, Lansky AJ, Na Y, Pocock S, Negoita M, Moussa I, Stone GW, et al. (2005) Low hematocrit predicts contrast-induced nephropathy after percutaneous coronary interventions. Kidney Int 67:706-713.

Pacher P, Beckman JS, and Liaudet L (2007) Nitric oxide and peroxynitrite in health and disease. Physiol Rev 87:315-424.

Pahade JK, LeBedis CA, Raptopoulos VD, Avigan DE, Yam CS, Kruskal JB and Pedrosa I (2011) Incidence of contrast-induced nephropathy in patients with multiple myeloma undergoing contrast-enhanced CT. AJR Am J Roentgenol 196: $1094-1101$
Palli E, Makris D, Papanikolaou J, Garoufalis G, Tsilioni I, Zygoulis P, and Zakynthinos E (2017) The impact of $\mathrm{N}$-acetylcysteine and ascorbic acid in contrast-induced nephropathy in critical care patients: an open-label randomized controlled study. Crit Care 21:269.

Patel K, King CA, and Jovin IS (2011) Angiotensin-converting enzyme inhibitors and their effects on contrast-induced nephropathy after cardiac catheterization or percutaneous coronary intervention. Cardiovasc Revasc Med 12:90-93.

Peng PA, Wang L, Ma Q, Xin Y, Zhang O, Han HY, Liu XL, Ji QW, Zhou YJ, and Zhao YX (2015) Valsartan protects HK-2 cells from contrast media-induced apoptosis by inhibiting endoplasmic reticulum stress. Cell Biol Int 39:1408-1417.

Persson PB, Hansell P, and Liss P (2005) Pathophysiology of contrast mediuminduced nephropathy. Kidney Int 68:14-22.

Quintavalle C, Brenca M, De Micco F, Fiore D, Romano S, Romano MF, Apone F, Bianco A, Zabatta MA, Troncone G, et al. (2011) In vivo and in vitro assessment of pathways involved in contrast media-induced renal cells apoptosis. Cell Death Dis 2:e155.

Quintavalle C, Fiore D, De Micco F, Visconti G, Focaccio A, Golia B, Ricciardelli B, Donnarumma E, Bianco A, Zabatta MA, et al. (2012) Impact of a high loading dose of atorvastatin on contrast-induced acute kidney injury. Circulation 126 $3008-3016$.

Rees JA, Old SL, and Rowlands PC (1997) An ultrastructural histochemistry and light microscopy study of the early development of renal proximal tubular vacuolation after a single administration of the contrast enhancement medium "Iotrolan”. Toxicol Pathol 25:158-164.

Robinson MJ and Cobb MH (1997) Mitogen-activated protein kinase pathways. Curr Opin Cell Biol 9:180-186.

Romano G, Briguori C, Quintavalle C, Zanca C, Rivera NV, Colombo A, and Condorelli G (2008) Contrast agents and renal cell apoptosis. Eur Heart $J$ 29: $2569-2576$.

Rosenstock JL, Bruno R, Kim JK, Lubarsky L, Schaller R, Panagopoulos G, DeVita MV, and Michelis MF (2008) The effect of withdrawal of ACE inhibitors or angiotensin receptor blockers prior to coronary angiography on the incidence of contrast-induced nephropathy. Int Urol Nephrol 40:749-755.

Roza CA, Scaini G, Jeremias IC, Ferreira GK, Rochi N, Benedet J, Rezin GT, Vuolo F, Constantino LS, Petronilho FC, et al. (2011) Evaluation of brain and kidney energy metabolism in an animal model of contrast-induced nephropathy. Metab Brain Dis 26:115-122.

Sands JM (2012) Urine concentrating and diluting ability during aging. J Gerontol A Biol Sci Med Sci 67:1352-1357.

Scheitlin W, Martz G, and Brunner U (1960) [Acute renal failure following intravenous pyelography in multiple myeloma]. Schweiz Med Wochenschr 90:84-87.

Schick CS, Bangert R, Kübler W, and Haller C (2002) Ionic radiocontrast media disrupt intercellular contacts via an extracellular calcium-independent mechanism. Exp Nephrol 10:209-215.

Schoolwerth AC, Sica DA, Ballermann BJ, and Wilcox CS; Council on the Kidney in Cardiovascular Disease and the Council for High Blood Pressure Research of the American Heart Association (2001) Renal considerations in angiotensin converting enzyme inhibitor therapy: a statement for healthcare professionals from the Council on the Kidney in Cardiovascular Disease and the Council for High Blood Pressure Research of the American Heart Association. Circulation 104:1985-1991. Schreiner GE (1966) Nephrotoxicity and diagnostic agents. JAMA 196:413-415.

Schröder M and Kaufman RJ (2005) The mammalian unfolded protein response. Annu Rev Biochem 74:739-789.

Sekiguchi H, Ajiro Y, Uchida Y, Jujo K, Iwade K, Tanaka N, Shimamoto K, Tsurumi Y, Kawana M, and Hagiwara N (2017) Contrast-induced nephropathy and oxygen pretreatment in patients with impaired renal function. Kidney Int Rep 3:65-72.

Solomon R and Dauerman HL (2010) Contrast-induced acute kidney injury. Circulation 122:2451-2455.

Spargias K, Alexopoulos E, Kyrzopoulos S, Iokovis P, Greenwood DC, Manginas A, Voudris V, Pavlides G, Buller CE, Kremastinos D, et al. (2004) Ascorbic acid prevents contrast-mediated nephropathy in patients with renal dysfunction undergoing coronary angiography or intervention [published correction appears in Circulation (2005) 111:379]. Circulation 110:2837-2842

Stacul F, Bertolotto M, Thomsen HS, Pozzato G, Ugolini D, Bellin MF, Bongartz G, Clement O, Heinz-Peer G, van der Molen A, et al.; ESUR Contrast Media Safety Committee (2018) Iodine-based contrast media, multiple myeloma and monoclonal gammopathies: literature review and ESUR Contrast Media Safety Committee guidelines. Eur Radiol 28:683-691.

Stokes JM and Bernard HR (1961) Nephrotoxicity of iodinated contrast media: quantitative effects of high concentration upon glomerular and tubular functions. Ann Surg 153:299-309.

Stoll LL, McCormick ML, Denning GM, and Weintraub NL (2004) Antioxidant effects of statins. Drugs Today (Barc) 40:975-990.

Stratta P, Quaglia M, Airoldi A, and Aime S (2012) Structure-function relationships of iodinated contrast media and risk of nephrotoxicity. Curr Med Chem 19 $736-743$

Su J, Zou W, Cai W, Chen X, Wang F, Li S, Ma W, and Cao Y (2014) Atorvastatin ameliorates contrast medium-induced renal tubular cell apoptosis in diabetic rats via suppression of Rho-kinase pathway. Eur $J$ Pharmacol 723:15-22.

Swan SK (1997) Aminoglycoside nephrotoxicity. Semin Nephrol 17:27-33.

Swick M (1930) Intravenous urography by means of the sodium salt of 5-iodo2pyridon-N-acetic acid. J Am Med Assoc 95:1403-1409.

Szegezdi E, Logue SE, Gorman AM, and Samali A (2006) Mediators of endoplasmic reticulum stress-induced apoptosis. EMBO Rep 7:880-885.

Takasu O, Gaut JP, Watanabe E, To K, Fagley RE, Sato B, Jarman S, Efimov IR, Janks DL, Srivastava A, et al. (2013) Mechanisms of cardiac and renal dysfunction in patients dying of sepsis. Am J Respir Crit Care Med 187:509-517.

Tang C, Han H, Yan M, Zhu S, Liu J, Liu Z, He L, Tan J, Liu Y, Liu H, et al. (2018) PINK1-PRKN/PARK2 pathway of mitophagy is activated to protect against renal ischemia-reperfusion injury. Autophagy 14:880-897. 
Tasanarong A, Vohakiat A, Hutayanon P, and Piyayotai D (2013) New strategy of $\alpha$ and $\gamma$-tocopherol to prevent contrast-induced acute kidney injury in chronic kidney disease patients undergoing elective coronary procedures. Nephrol Dial Transplant 28:337-344.

Tepel M, van der Giet M, Schwarzfeld C, Laufer U, Liermann D, and Zidek W (2000) Prevention of radiographic-contrast-agent-induced reductions in renal function by acetylcysteine. $N$ Engl $J$ Med 343:180-184.

Tervahartiala P, Kivisaari L, Kivisaari R, Vehmas T, and Virtanen I (1997) Structural changes in the renal proximal tubular cells induced by iodinated contrast media. Nephron 76:96-102.

Tervahartiala P, Kivisaari L, Kivisaari R, Virtanen I, and Standertskjöld-Nordenstam CG (1991) Contrast media-induced renal tubular vacuolization. A light and electron microscopic study on rat kidneys. Invest Radiol 26:882-887.

Thomsen HS and Morcos SK (2003) Contrast media and the kidney: European Society of Urogenital Radiology (ESUR) guidelines. Br J Radiol 76:513-518.

Tongqiang L, Shaopeng L, Xiaofang Y, Nana S, Xialian X, Jiachang H, Ting Z and Xiaoqiang D (2016) Salvianolic acid B prevents iodinated contrast mediainduced acute renal injury in rats via the PI3K/Akt/Nrf2 pathway. Oxid Med Cell Longev 2016:7079487.

Toprak O (2007) Conflicting and new risk factors for contrast induced nephropathy. $J$ Urol 178:2277-2283.

Toprak O, Cirit M, Tanrisev M, Yazici C, Canoz O, Sipahioglu M, Uzum A, Ersoy R, and Sozmen EY (2008) Preventive effect of nebivolol on contrast-induced nephropathy in rats. Nephrol Dial Transplant 23:853-859.

Toso A, Maioli M, Leoncini M, Gallopin M, Tedeschi D, Micheletti C, Manzone C, Amato M, and Bellandi F (2010) Usefulness of atorvastatin $(80 \mathrm{mg})$ in prevention of contrast-induced nephropathy in patients with chronic renal disease. Am J Cardiol 105:288-292.

Touati C, Idee JM, Deray G, Santus R, Balut C, Beaufils H, Jouanneau C, Bourbouze R, Doucet D, and Bonnemain B (1993) Modulation of the renal effects of contrast media by endothelium-derived nitric oxide in the rat. Invest Radiol 28:814-820.

Tran M, Tam D, Bardia A, Bhasin M, Rowe GC, Kher A, Zsengeller ZK, AkhavanSharif MR, Khankin EV, Saintgeniez M, et al. (2011) PGC- $1 \alpha$ promotes recovery after acute kidney injury during systemic inflammation in mice. J Clin Invest 121 : 4003-4014.

Tropeano F, Leoncini M, Toso A, Maioli M, Dabizzi L, Biagini D, Villani S, and Bellandi F (2016) Impact of rosuvastatin in contrast-induced acute kidney injury in the elderly: post hoc analysis of the PRATO-ACS trial. $J$ Cardiovasc Pharmacol Ther 21:159-166.

Tsai TT, Patel UD, Chang TI, Kennedy KF, Masoudi FA, Matheny ME, Kosiborod M, Amin AP, Messenger JC, Rumsfeld JS, et al. (2014) Contemporary incidence, predictors, and outcomes of acute kidney injury in patients undergoing percutaneous coronary interventions: insights from the NCDR Cath-PCI registry. JACC Cardiovasc Interv 7:1-9.

Ueda J, Nygren A, Hansell P, and Ulfendahl HR (1993) Effect of intravenous contrast media on proximal and distal tubular hydrostatic pressure in the rat kidney. Acta Radiol 34:83-87.

Visipaque (iodixanol). (2006) Package insert. GE-Healthcare, Mississauga, ON, Canada.

Wallingford VH (1953) The development of organic iodine compounds as x-ray contrast media. J Am Pharm Assoc Am Pharm Assoc 42:721-728.

Wang Y, Zhang H, Yang Z, Miao D, and Zhang D (2018) Rho kinase inhibitor, fasudil, attenuates contrast-induced acute kidney injury. Basic Clin Pharmacol Toxicol 122:278-287.
Weisbord SD, Gallagher M, Jneid H, Garcia S, Cass A, Thwin SS, Conner TA, Chertow GM, Bhatt DL, Shunk K, et al.; PRESERVE Trial Group (2018) Outcomes after angiography with sodium bicarbonate and acetylcysteine. $N$ Engl J Med 378: $603-614$

Weisbord SD and Palevsky PM (2008) Prevention of contrast-induced nephropathy with volume expansion. Clin J Am Soc Nephrol 3:273-280.

Widmark JM (2007) Imaging-related medications: a class overview. Proc Bayl Univ Med Cent 20:408-417.

Wiersinga WJ, Leopold SJ, Cranendonk DR, and van der Poll T (2014) Host innate immune responses to sepsis. Virulence 5:36-44.

Wu CT, Sheu ML, Tsai KS, Weng TI, Chiang CK, and Liu SH (2010) The role of endoplasmic reticulum stress-related unfolded protein response in the radiocontrast medium-induced renal tubular cell injury. Toxicol Sci 114:295-301.

Wu CT, Weng TI, Chen LP, Chiang CK, and Liu SH (2013) Involvement of caspase12-dependent apoptotic pathway in ionic radiocontrast urografin-induced renal tubular cell injury. Toxicol Appl Pharmacol 266:167-175.

Xiao X, Hu Y, Quirós PM, Wei Q, López-Otín C, and Dong Z (2014) OMA1 mediates OPA1 proteolysis and mitochondrial fragmentation in experimental models of ischemic kidney injury. Am J Physiol Renal Physiol 306:F1318-F1326.

Xie XC, Cao Y, Yang X, Xu QH, Wei W, and Wang M (2017) Relaxin attenuates contrast-induced human proximal tubular epithelial cell apoptosis by activation of the PI3K/Akt signaling pathway in vitro. BioMed Res Int 2017: 2869405 .

Yang D and Yang D (2013) Role of intracellular $\mathrm{Ca}^{2+}$ and $\mathrm{Na}^{+} / \mathrm{Ca}^{2+}$ exchanger in the pathogenesis of contrast-induced acute kidney injury. BioMed Res Int $\mathbf{2 0 1 3}$ 678456.

Yang D, Yang D, Jia R, and Ding G (2013) Selective inhibition of the reverse mode of $\mathrm{Na}^{+} / \mathrm{Ca}^{2+}$ exchanger attenuates contrast-induced cell injury. Am J Nephrol 37: 264-273.

Yang JS, Peng YR, Tsai SC, Tyan YS, Lu CC, Chiu HY, Chiu YJ, Kuo SC, Tsai YF, Lin PC, et al. (2018a) The molecular mechanism of contrast-induced nephropathy $(\mathrm{CIN})$ and its link to in vitro studies on iodinated contrast media (CM). Biomedicine (Taipei) 8:1.

Yang X, Yan X, Yang D, Zhou J, Song J, and Yang D (2018b) Rapamycin attenuates mitochondrial injury and renal tubular cell apoptosis in experimental contrastinduced acute kidney injury in rats. Biosci Rep 38:BSR20180876.

Yang Y, Yang D, Yang D, Jia R, and Ding G (2014) Role of reactive oxygen speciesmediated endoplasmic reticulum stress in contrast-induced renal tubular cell apoptosis. Nephron, Exp Nephrol 128:30-36.

Yeganehkhah MR, Iranirad L, Dorri F, Pazoki S, Akbari H, Miryounesi M, Vahedian M, Nazeri A, Hosseinzadeh F, and Vafaeimanesh J (2014) Comparison between three supportive treatments for prevention of contrast-induced nephropathy in high-risk patients undergoing coronary angiography. Saudi J Kidney Dis Transpl 25:1217-1223.

Yokomaku Y, Sugimoto T, Kume S, Araki S, Isshiki K, Chin-Kanasaki M, Sakaguchi M, Nitta N, Haneda M, Koya D, et al. (2008) Asialoerythropoietin prevents contrast-induced nephropathy. J Am Soc Nephrol 19:321-328.

Address correspondence to: Monica A. Valentovic, Department of Biomedical Sciences, 1 Marshall Drive, Room 435 G, Byrd Biotech Science Buiding, Joan C. Edwards School of Medicine, Marshall University, Huntington, WV 25755-9308. E-mail: valentov@marshall.edu 